\title{
LOS PROBLEMAS ECONÓMICOS SURGIDOS EN 2013 QUE NO SE PREVIERON CON ANTICIPACIÓN.
}

\author{
Emilio Margain Manautou ${ }^{1}$
}

Sumario: Introducción. I Omisiones. II Pretensiones. III. Recomendaciones

Resumen

En forma suscinta el autor resume magistralmente el origen,consecuencias y correcciones legislativas para atenuar los problemas económicos surgidos en México, por el manejo del petróleo en el 2013, precisando recomendaciones al respecto.

Palabras clave: petróleo,economía,efectos tributarios

\begin{abstract}
In succinct form, the author masterfully summarizes the origin, consequences and legislative corrections to mitigate the economic problems arising in Mexico, by the management of oil in 2013, specifying recommendations in this regard.
\end{abstract}

Key words. Oil,economy, tax effects

Introducción

Agradezco la amable invitación de Adria González Beltrones para aportar este pequeño trabajo, por lo que aprovechando ello trataré de forma breve el origen de los problemas

${ }^{1}$ Distinguido Catedrático Emérito de Derecho Fiscal y Administrativo de la Universidad Nacional Autónoma de México y de otras Universidades Públicas y Privadas del País y del extranjero. Doctor Honoris causa por CENIJUR Centro de Investigación Jurídica Puebla. Reconocido Profesional de los Foros Jurídicos Nacionales y Locales en el ámbito Administrativo y Fiscal. Autor de mas de 20 obras en la materia actualizadas cada año, tales como: "Introducción al Estudio del Derecho Tributario", "Introducción al Estudio del Derecho Administrativo, "De lo Contencioso Administrativo de Anulación o de llegitimidad, Política Fiscal, Recursos Administrativos entre otras. "Distinguido Miembro Invitado de la Academia de Derecho Administrativo" a partir de la entrada en vigor(1991) de la Ley 4 que regula orgánicamente la vida académica de la Universidad de Sonora. 
que con el petróleo México ha tenido y tiene nuestro país, que no se previeron para buscar atenuarlos con la anticipación debida, que fueron:

\section{Antecedentes}

México no es miembro de la OPEP, a petición del vecino del norte, pero como expresó el Presidente José López Portillo, entonces en funciones: "México al no estar limitado para enajenar petróleo no se convertirá en un esquirol, pues su precio por barril de petróleo crudo será el de los países miembros de la OPEP”. Y México a vender y vender petróleo crudo sin limitación alguna y, en diciembre de 1981, se leyó en el periódico EXCELSIOR que Arabia Saudí, en forma muy breve, nos decía: "México, no sigas haciendo lo que estás haciendo con el petróleo porque te vas a arrepentir" y el 10. de septiembre de 1982, México estaba hincado ante una deuda impagable en dólares americanos que el gobierno federal y sector privado habían contraído, consecuencia de la baja del precio de importación del petróleo acordado por los países miembros de la OPEP, forma en que castigaron a México, pues el nuevo precio no alcanzaba para pagar a los acreedores extranjeros. Se decretó ese día la estatización de la banca y el control de divisas, que el siguiente Presidente Miguel de la Madrid Hurtado primero liberó el control de divisas y posteriormente enajenó la banca.

\section{Nuestros Dias}

Durante el último debate que tuvieron en 2012 John McCain, candidato del Partido Republicano a la Presidencia de los Estados Unidos de América y el Presidente Barack Obama del Partido Demócrata, aquél le espetó, en el programa televisivo que se estaba trasmitiendo, que ¿por qué los Estados Unidos estaba importando en perjuicio de la economía del país fuertes cantidades de petróleo crudo sin buscar reducción alguna?, lo cual ocasionó que se sonriera Obama y le contestara de inmediato: "Nunca como ahora los Estados Unidos ha estado disminuyendo la importación de petróleo crudo al estar en plena producción todos los pozos petroleros del país". Quedé sorprendido al escuchar ello pues significaba que en cuestión de poco tiempo se empezarían a sentir efectos económicos nocivos, lo cual, a mediados de 2013, se empezaron a observar. Que a México el vecino del norte no le redujera sus adquisiciones de petróleo crudo derivó de 
que sus reducciones de compras a países petroleros miembros de la OPEP las enajenaba, a países europeos y, probablemente, a Israel, para reducir los costos de transportación.

\section{Omisiones}

Lamentablemente en México no se procedió a los estudios de los efectos de la disminución de las adquisiciones de petróleo crudo por parte de los Estados Unidos y baja del precio, que comenté en privado, disminuyendo el precio de enajenación paulativamente hasta que llegó a $\$ 50.00$ dólares americanos por barril y hoy ha estado fluctuando en $\$ 40.00$ dólares por barril con perjuicio de todos los países exportadores de petróleo crudo. ¿Por qué no se reflejó en estudios los efectos económicos de que Estados Unidos estaba disminuyendo sus compras de petróleo crudo? ¿Qué pasó con los economistas de Petróleos Mexicanos y de los economistas mexicanos que inclusive buen número realizaron estudios en el extranjero y guardaron silencio? O quizás, ni repararon en lo que Obama había dado a conocer.

El fisco federal mexicano o los técnicos de la Hacienda Pública Mexicana no se percataron de los efectos negativos de que los Estados Unidos estaba disminuyendo sus compras de petróleo crudo en el extranjero y por ende el precio, procediendo a formular cuáles serían las reformas tributarias correspondientes y no las que sorprendieron a todos los contribuyentes al buscar con ello atenuar en algo el problema económico que se le veía venir al país, pues no se recuerda de la elaboración de estudios doctrinarios sobre las consecuencias de que todos los pozos petroleros de los Estados Unidos estaban en plena explotación.

\section{Pretensiones}

Con las reformas tributarias que entraron en vigor el 10. de enero de 2014, se pretendió atenuar los efectos económicos que en la recaudación tributaria iba a padecer el fisco federal y, por consiguiente, la participación a la CDMX, Estados y Municipios, los presupuestos del Poder Legislativo y el Poder Judicial Federal. Se incrementó el impuesto al valor agregado fronterizo y, como consecuencia, el impuesto a productos del petróleo, que afectó a la zona fronteriza del norte, aplaudiendo la reforma los contribuyentes de los establecimientos comerciales de la zona fronteriza del sur de los Estados Unidos, 
surgiendo extensas colas de peatones y de automovilistas mexicanos para cruzar la frontera al tener las entidades vecinas un impuesto general a las ventas menor que el IVA nuestro afectándose también la zona fronteriza del sur del país, al contraerse las compras de consumidores de Guatemala y el Salvador.

\section{Recomendaciones}

Por ello es necesario cuando haya un nuevo impuesto o incremento del existente necesariamente estudiar los efectos económicos que se producirán: ¿serán nocivos? o ¿a quién afectará más? ¿Al contribuyente o al mediano y bajo consumidor final? Este estudio no se efectuó.

Cuando se modifica el sistema tributario en vigor no solo se deben estudiar las novedades que se incorporan a él, sino cómo afectarán a la economía del país o a los contribuyentes o esencialmente al pequeño o mediano consumidor final. Al reducirse las deducciones el productor y el comerciante aumentan los precios.

Las raíces de la materia tributaria son eminentemente económicas. No solo debe estudiarse las novedades, sino si alteraran, en forma leve o no la economía del país y a qué consumidor final, de manera especial, se afectará. Estúdiese también las causas de ello, lo que las originó.

Y enseguida surgió el gasolinazo.

Estúdiese el derecho tributario, no se vuelvan prácticos del mismo. 